\title{
Control of potassium tantalate niobate thin film crystal phase and orientation by atomic layer deposition
}

Cite as: J. Vac. Sci. Technol. A 37, 020904 (2019); https://

doi.org/10.1116/1.5063925@jva.2019.ALD2019.issue-1

Submitted: 02 October 2018 . Accepted: 17 December 2018 . Published Online: 11 January 2019

Justin R. Bickford, Henrik Hovde Sønsteby, Nicholas A. Strnad, Peter Y. Zavalij, and Robert C. Hoffman

\section{COLLECTIONS}

Paper published as part of the special topic on 2019 Special Collection on Atomic Layer Deposition (ALD) and Collection

Note: This paper is part of the 2019 special collection on Atomic Layer Deposition (ALD).
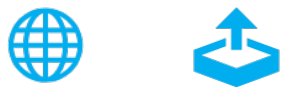

\section{ARTICLES YOU MAY BE INTERESTED IN}

Toward epitaxial ternary oxide multilayer device stacks by atomic layer deposition

Journal of Vacuum Science \& Technology A 37, 020602 (2019); https://

doi.org/10.1116/1.5081997

Control of growth orientation in as-deposited epitaxial iron-rich nickel ferrite spinel

Journal of Vacuum Science \& Technology A 37, 021502 (2019); https://

doi.org/10.1116/1.5082012

Surface chemistry of atomic layer deposition: A case study for the trimethylaluminum/water process

Journal of Applied Physics 97, 121301 (2005); https://doi.org/10.1063/1.1940727

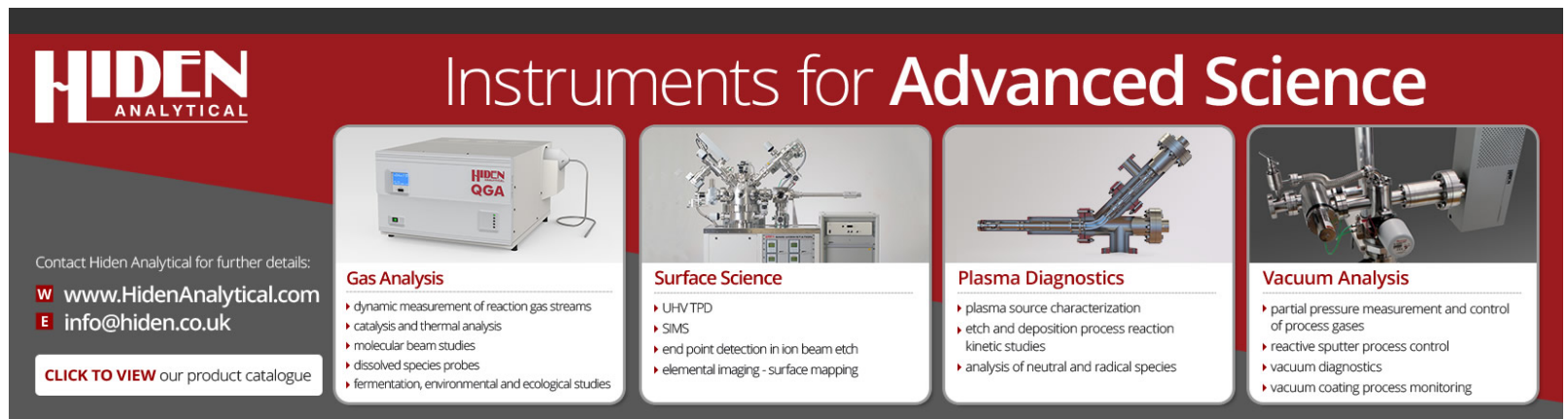




\title{
Control of potassium tantalate niobate thin film crystal phase and orientation by atomic layer deposition
}

\author{
Justin R. Bickford, ${ }^{1, a)}$ Henrik Hovde Sønsteby, ${ }^{2}$ Nicholas A. Strnad, ${ }^{3}$ Peter Y. Zavalij, ${ }^{4}$ \\ and Robert C. Hoffman ${ }^{1}$ \\ ${ }^{1}$ U.S. Army Research Laboratory, 2800 Powder Mill Rd., Adelphi, Maryland 20783 \\ ${ }^{2}$ Department of Chemistry, University of Oslo, Sem Salands vei 26, 0371 Oslo, Norway \\ ${ }^{3}$ General Technical Services, LLC, 1451 Route 34 South-Suite 301, Wall Township, New Jersey 07727 \\ ${ }^{4}$ Department of Chemistry and Biochemistry, University of Maryland, College Park, Maryland 20742
}

(Received 2 October 2018; accepted 17 December 2018; published 11 January 2019)

\begin{abstract}
Due to its appreciable electro-optical properties, potassium tantalate niobate (KTN) thin films of high quality are expected to enhance the functionality of integrated photonics optical modulators. Unfortunately, they are inherently hard to synthesize. Herein, the authors present atomic layer deposition (ALD) of oriented KTN for the first time. They study the variability in phase content with respect to potassium concentration across a variety of substrates. Films grown with a slight overstoichiometry in potassium show excellent crystal quality of a pure perovskite phase. Highly oriented films were obtained on substrates of a similar lattice constant to bulk potassium tantalate niobate. Nearly stoichiometric potassium contents yield films with similar quality, albeit with trace amounts of pyrochlore. Potassium deficient films consist of an overwhelming amount of pyrochlore. Phase control and orientation control are essential when considering device integration of optical modulators. The authors believe that ALD is an ideal technique to obtain KTN thin films with high growth control. Published by the AVS.

https://doi.org/10.1116/1.5063925
\end{abstract}

\section{INTRODUCTION}

Potassium tantalate niobate (KTN) is an important paraelectric/ ferroelectric material with a strong electro-optic (EO) behavior useful for creating efficient integrated photonics optical modulators. A Kerr coefficient as high as $2.24 \times 10^{-14} \mathrm{~m}^{2} / \mathrm{V}^{2}$ has been reported, ${ }^{1-3}$ which is notably larger than other more prolific EO materials, e.g., $\mathrm{LiNbO}_{3}{ }^{4,5}$ Furthermore, unlike many other materials boasting strong Pockel's EO coefficients with undesirable anisotropic optical indices, KTN is a Kerr material which does not require poling and presents an isotropic optical index. The EO properties of KTN are strongest in the cubic paraelectric state just above the transition temperature to the tetragonal ferroelectric state. This Curie temperature $\left(\mathrm{T}_{\mathrm{C}}\right)$ is tunable by controlling the tantalum to niobium ratio in the fully miscible $\mathrm{KTaO}_{3}: \mathrm{KNbO}_{3}$ solid mixture. Prior investigations ${ }^{1-3,6}$ suggest that achieving $\mathrm{T}_{\mathrm{C}}$ around room temperature would require $\mathrm{KTa}_{\mathrm{x}} \mathrm{Nb}_{1-\mathrm{x}} \mathrm{O}_{3}$ with $0.6<x<0.7$. It is important to note that KTN is stable in two structure types: perovskite $\left(\mathrm{ABO}_{3}\right)$ and pyrochlore $\left(\mathrm{A}_{2} \mathrm{~B}_{2} \mathrm{O}_{6}\right)$. Only the former exhibits appreciable $\mathrm{EO}$ functionality, underlining the importance of achieving phase control.

Existing silicon based photonic integrated circuit (PIC) optical modulators rely on thermo-optic ${ }^{7}$ or free-carrier dispersion $^{8}$ effects, which have limited efficiency and speed. Incorporating KTN with its strong EO properties uniformly over large areas during the fabrication of integrated photonics would greatly enhance modulator performance; a key component

Note: This paper is part of the 2019 special collection on Atomic Layer Deposition (ALD).

${ }^{a)}$ Electronic mail: justin.r.bickford.civ@mail.mil of all photonic systems. Because of its great potential, many growth methods have been investigated to deposit KTN: bulk growth, ${ }^{3,9-11}$ solgel, ${ }^{12-17}$ pulsed laser deposition (PLD), ${ }^{18-25}$ and metalorganic chemical vapor deposition (MOCVD). ${ }^{26}$

The bulk growth process is slow and produces boules only about $4 \mathrm{~cm}$ wide. The growth generates stress induced birefringence and zone boundaries through the body of the boule. Furthermore, the composition is difficult to control throughout the growth leading to composition gradients. These defects limit the useful device material that can be obtained. Monolithic integration is also difficult with bulk KTN due to cutting, polishing, and bonding complications. Available bulk KTN sizes would also limit integration to patchwork bonding on contemporary silicon PIC $300 \mathrm{~mm}$ wafers.

Solgel methods yield fair stoichiometric control and uniformity across large areas, but requires tedious iterations of deposition, pyrolysis, and high temperature annealing to grow relevant film thicknesses. It also tends to suffer from precursor chemical pre-reactions and crack formation due to shrinkage during solvent evaporation. Carbon contamination is also difficult to avoid. Solgel KTN films need to be annealed beyond $750{ }^{\circ} \mathrm{C}$ to obtain a predominately perovskite phase. ${ }^{13-15,17}$ Annealing beyond $900^{\circ} \mathrm{C}$ results in conversion to pyrochlore. $\mathrm{Lu}$ and Kuang ${ }^{15}$ and Buršs ${ }^{\prime} \mathrm{k}$ et al. ${ }^{17}$ similarly achieved mostly polycrystalline perovskite on $\mathrm{MgO}(100), \mathrm{SrTiO}_{3}$ (100), and some on YSZ (100), $\mathrm{LaAlO}_{3}(100)$, and $\mathrm{Al}_{2} \mathrm{O}_{3}$ (1102). Native oxide coated Si (111), Pt coated Si (111), and quartz showed only pyrochlore.

PLD requires growth temperatures of $700-800{ }^{\circ} \mathrm{C}$ and does not deposit films uniformly over adequately large areas to be included in monolithic PIC manufacturing. PLD deposition 
chambers are typically limited to $<10 \mathrm{~cm}$. Resulting films typically contain inclusions, voids, coarse grains, and splattered source material of varied composition. Yilmaz et al. ${ }^{18}$ showed that careful addition of $\mathrm{KNO}_{3}$ to a KTN target was needed to obtain stoichiometric KTN films via PLD. While Jung et al. ${ }^{23}$ was only able to obtain pyrochlore KTN on ITO, $\mathrm{ZnO}$, and $\mathrm{SrTiO}_{3}$ buffer layers on glass substrates, Knauss et al., ${ }^{20}$ Yang et $a l .{ }^{22}$ and Bouyasfi et $a .^{25}$ were each similarly able to deposit the perovskite phase on $\mathrm{MgO}$ and $\mathrm{SrTiO}_{3}$.

Nichols ${ }^{26}$ grew KTN by MOCVD on a variety of substrates: $\mathrm{MgAl}_{2} \mathrm{O}_{4}$ (100), $\mathrm{SrTiO}_{3}(100), \mathrm{LaAlO}_{3}(100)$, and $\mathrm{SrLaAlO}_{4}$ (100). However, MOCVD requires soaking the substrates at high temperature (around $800{ }^{\circ} \mathrm{C}$ ), which is not compatible with silicon photonics monolithic processes.

Atomic layer deposition (ALD) is, in comparison with most other techniques, a low temperature chemical vapor deposition method capable of conformally coating large area substrates with high density films. It is based on self-limiting layer-by-layer growth, achieved by sequentially pulsing cation precursors followed by an oxidation step. ${ }^{27}$ The precursors are separated in time or space by an inert gas purge. ALD is routinely used to achieve exceptionally fine composition and thickness control with high reproducibility. The technique has traditionally been used to deposit high- $\kappa$ binary oxides with extreme conformality, and is presently used on an industrial scale for gate oxides in ultrasmall node transistor technology. In recent years, however, ALD of complex oxides has gained considerable attention. ${ }^{28}$

The sequential nature of ALD limits the rate of deposition, and thus the technique is considered slow by many. However, large deposition area allows coating of a large number of devices, making the throughput viable on industrial scales. ALD is usually employed to deposit ultrathin films; however, film thickness on the order of $200 \mathrm{~nm}$ needed for PIC modulators is attainable.

ALD of alkali metal containing materials has mostly been focused around lithium compounds for use in battery technology. In 2013, ferroelectric $\mathrm{LiNbO}_{3}$ was achieved, ${ }^{29,30}$ showing that ALD can also facilitate deposition of high quality alkali metal containing functional oxides. The advent of sodium and potassium deposition by ALD in 2014 (Ref. 31) demonstrated that highly regarded functional material such as sodium potassium niobate could be achieved. ${ }^{32}$ Sønsteby et al. presented a proof-of-concept for obtaining potassium tantalate niobate solid solution thin films, but a systematic study of this material via ALD has not been reported until now.

It is important to deposit KTN with good crystallinity and composition control predominately of perovskite phase without sacrificing optical quality. Orientation control is important to maximally utilize the material's EO capability. ${ }^{33}$ With this study, we report growth of oriented KTN by ALD. We employ a growth temperature of only $250{ }^{\circ} \mathrm{C}$ and a postannealing temperature of $650^{\circ} \mathrm{C}$ for a short duration $(10$ min). This could easily be achieved either during or after PIC fabrication without affecting other critical process steps. We show that crystalline orientation can be selected by careful choice of substrate and that a pure perovskite phase can be achieved by tuning the potassium concentration.

\section{EXPERIMENT}

Thin films were deposited in an F-120 Sat reactor (ASM Microchemistry). All films were deposited at a reactor temperature of $250^{\circ} \mathrm{C}$. Nitrogen purging gas was supplied from gas cylinders (Praxair, 99.999\%), run through a Mykrolis purifier, and maintained at a $300 \mathrm{~cm}^{3} \mathrm{~min}^{-1}$ primary flow rate. Reactor operating pressure was maintained at $2.8 \mathrm{mbar}$ throughout the depositions.

All depositions were carried out using $\mathrm{KO}^{\mathrm{t}} \mathrm{Bu}$ (Aldrich, 97\%), $\mathrm{Nb}(\mathrm{OEt})_{5}$ (Aldrich, 99\%), and $\mathrm{Ta}(\mathrm{OEt})_{5}$ (Aldrich, 99\%) as metal precursors. The cation precursors were supplied from open boats inside the reactor, held at 150, 70, and $70^{\circ} \mathrm{C}$, respectively. De-ionized water was used at the oxygen source, supplied from an external bubbler held at room temperature. Pulse durations were set to $3 \mathrm{~s}$ for all metal precursors and $2 \mathrm{~s}$ for the water pulses. All purge durations were set to $3 \mathrm{~s}$. These pulse and purge times are based on experience achieving self-limiting growth with the same precursors for deposition of similar materials in the same ALD-reactors throughout our prior studies.

Si (100) substrates were used to map thickness and composition. Selected depositions were carried out using YSZ (100), $\mathrm{SrLaAlO}_{4}$ (100) (LSAT), $\mathrm{SrTiO}_{3}$ (100), (STO), $\mathrm{Y}_{3} \mathrm{Al}_{5} \mathrm{O}_{12}$ (100) (YAG), $\mathrm{MgO}$ (100), and $\mathrm{Al}_{2} \mathrm{O}_{3}$ (1102) based on their strained, but similar lattice constants to KTN's bulk value of $3.996 \AA$, as listed in Table I.

We targeted KTN compositions with $10 \%$ excess, stoichiometric, and $10 \%$ deficient $\mathrm{K}$ concentrations. $\mathrm{K}$ concentration was measured via $\mathrm{X}$-ray fluorescence spectroscopy, using a Panalytical Axios Max Minerals x-ray fluorescence system equipped with a $4 \mathrm{~kW}$ Rh-tube, running with Omnian and Stratos options for standardless measurements of thin films.

Films were postannealed in a rapid thermal annealer in air ambient, soaking to $220^{\circ} \mathrm{C}$ in $180 \mathrm{~s}$, then heated to $650^{\circ} \mathrm{C}$ for $900 \mathrm{~s}$ at a rate of approximately $15^{\circ} \mathrm{C} / \mathrm{s}$. Crystallographic surveys were conducted on a Bruker C2 Discover x-ray diffraction (XRD) tool at substrate orientations of $8^{\circ}, 15.5^{\circ}$, $23^{\circ}, 30.5^{\circ}$, and $38^{\circ}$, and detector array center angles of $20^{\circ}$, $35^{\circ}, 50^{\circ}, 65^{\circ}$, and $80^{\circ}$ to avoid overwhelming scattering from the substrate. This was done to avoid confusion when comparing scattering across the different substrates. Crystal quality and orientation details were measured via $2 \theta$ scans using a Bruker D8 Discover diffractometer (Göbel mirror, Vantec500 area detector, $\mathrm{Cu} \mathrm{K} \alpha$ radiation) and $\varphi-\chi$ pole figure scans using a PANalytical X'Pert Pro MRD diffractometer $(\mathrm{Cu} \mathrm{K} \alpha$ radiation).

\section{RESULTS AND DISCUSSION}

We investigated the relationship between pulsed and deposited cation ratios to ensure sufficient compositional control. For ALD, this is complicated for a quaternary system, as changing the pulsed ratio for one cation precursor will affect the growth of the other two. This means that finding a simple relationship between the pulsed and deposited composition is not necessarily possible. We theorized, however, that this system will behave pseudoternary due to the very similar structure and chemistry of $\mathrm{Nb}(\mathrm{OEt})_{5}$ and 
TABLE I. Potassium tantalate niobate (KTN) thin film crystal phase, orientation, and quality results from XRD measurements for $110 \%$, $96 \%$, and $83 \%$ K, respectively. KTN preferred substrate lattice spacing also shown. oP: oriented polycrystalline; uP: unoriented polycrystalline; a: amorphous; sO: single orientation.

\begin{tabular}{|c|c|c|c|c|c|c|c|c|}
\hline \multirow[b]{2}{*}{ Substrate } & \multirow{2}{*}{$\begin{array}{c}\text { Lattice } \\
\text { constant }(\AA)\end{array}$} & \multirow{2}{*}{$\begin{array}{l}\text { KTN preferred } \\
\text { spacing }(\AA)\end{array}$} & \multicolumn{2}{|c|}{$110 \% \mathrm{~K}$} & \multicolumn{2}{|c|}{$96 \% \mathrm{~K}$} & \multicolumn{2}{|c|}{$83 \% \mathrm{~K}$} \\
\hline & & & Perovskite & Pyrochlore & Perovskite & Pyrochlore & Perovskite & Pyrochlore \\
\hline (100) YSZ & 5.125 & (110) 3.627 & (110) oP + uP & None & $\mathrm{uP}$ & None & None & Trace uP \\
\hline (100) $\mathrm{Si}$ & 5.431 & (110) 3.840 & a & $\mathrm{a}$ & $\mathrm{a}$ & $\mathrm{a}$ & a & a \\
\hline (100) LSAT & 3.868 & (100) 3.868 & (100) sO & None & $(100) \mathrm{sO}$ & Trace uP & Trace uP & $\mathrm{uP}$ \\
\hline (100) STO & 3.905 & 3.905 & (100) sO & None & $(100) \mathrm{sO}$ & Some uP & None & $\mathrm{uP}$ \\
\hline (100) YAG & 12.010 & (100) $3 \times 4.003$ & $\mathrm{uP}$ & None & - & - & Trace uP & uP \\
\hline (100) $\mathrm{MgO}$ & 4.216 & $\begin{array}{l}(100) \\
4.216\end{array}$ & (100) oP + uP & None & $(100) \mathrm{oP}+\mathrm{uP}$ & Some uP & Trace uP & uP \\
\hline (1102) $\mathrm{Al}_{2} \mathrm{O}_{3}$ & $4.785,12.991$ & $\frac{(1102)}{4.323}$ & uP & None & uP & None & None & $\mathrm{uP}$ \\
\hline
\end{tabular}

$\mathrm{Ta}(\mathrm{OEt})_{5}$. Both precursors are dimers in the gas phase, and the ionic radius of $\mathrm{Nb}^{5+}$ and $\mathrm{Ta}^{5+}$ is the same $(0.64 \AA$ in a six coordinated environment).

We studied the potassium content and $\mathrm{Ta}: \mathrm{Nb}$ variation as a function of the pulsed $\mathrm{K}:(\mathrm{K}+\mathrm{Nb}+\mathrm{Ta})$-ratio, while keeping the pulsed Ta:Nb-ratio constant (Fig. 1). A general expression for the employed ALD supercycle is

$$
\begin{aligned}
n & \times\left(\mathrm{KO}^{\mathrm{t}} \mathrm{Bu}+\mathrm{H}_{2} \mathrm{O}\right)+m \times\left\{2 \times\left[\left(\mathrm{Ta}(\mathrm{OEt})_{5}+\mathrm{H}_{2} \mathrm{O}\right]\right.\right. \\
& \left.+\left[\mathrm{Nb}(\mathrm{OEt})_{5}+\mathrm{H}_{2} \mathrm{O}\right]\right\},
\end{aligned}
$$

where $n$ and $m$ determine the ratio between alkali metal and group $\mathrm{V}$ metal, respectively. The 2:1 pulsed ratio between $\mathrm{Ta}$ and $\mathrm{Nb}$ was chosen to comply with the wanted $\mathrm{Ta}: \mathrm{Nb}$-ratio in the end product $\left(\mathrm{KTa}_{\mathrm{x}} \mathrm{Nb}_{1-\mathrm{x}} \mathrm{O}_{3}, 0.6<x<0.7\right)$.

The potassium content increases rapidly for small pulsed $\mathrm{K}$-ratios, which is in agreement with previous reports. Close to stoichiometric $\mathrm{K}(\mathrm{Ta}, \mathrm{Nb}) \mathrm{O}_{3}$ is obtained for 1:4 pulsed ratio

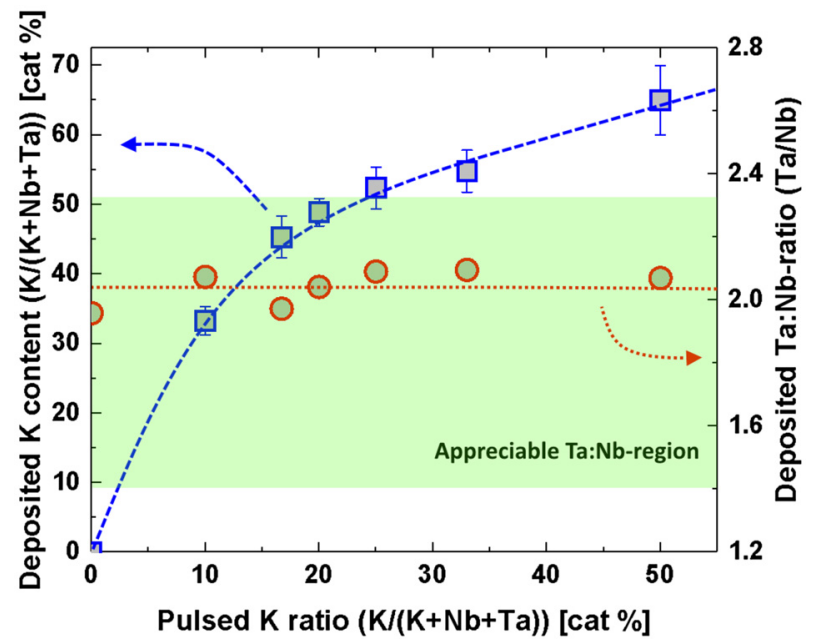

FIG. 1. Deposited potassium content and deposited Ta:Nb-ratio as a function of the pulsed potassium ratio. All films are deposited with a Ta:Nb pulsed ratio of 2. Blue dashed line is a guide for the eye to show the relationship between the pulsed and deposited potassium content. The red dotted line marks the average Ta:Nb-ratio in the deposited films. The green area shows the boundaries of the acceptable Ta:Nb-ratio in the films $\left(\mathrm{KTa}_{x} \mathrm{Nb}_{1-x} \mathrm{O}_{3}, 0.6\right.$ $<x<0.7)$. between $\mathrm{K}$ and $\mathrm{Ta} / \mathrm{Nb}$. It is also clear that the deposited Ta:Nb-ratio does not change dramatically upon varying the pulsed amount of potassium, which confirms the theory that the system behaves pseudoternary. Furthermore, we show the necessary cation control to obtain films with compositions very close to the wanted KTN phase. Note that excess $\mathrm{K}$ samples had their available $\mathrm{K}$ react with water vapor in the air after removal from the growth chamber and generated a cloudiness on some of the films, probably as a result of formation of $\mathrm{K}(\mathrm{OH})$ and/or $\mathrm{K}_{2} \mathrm{CO}_{3}$. This effect was more prevalent on a preliminary sample where the $\mathrm{K}$ content ended up $28 \%$ in excess, compared to stoichiometric KTN. Too much excess $\mathrm{K}$ may lead to optical transmission degradation and should be avoided.

Previous reports have shown that the structure of KTN is very dependent on the potassium content. We therefore studied understoichiometric, stoichiometric, and overstoichiometric films with respect to potassium, to explore phase control to obtain purely perovskite KTN. Figures $2-4$ show specular $\mathrm{x}$-ray diffraction for KTN films grown with $\mathrm{K}$ concentrations of $110 \%, 96 \%$, and $83 \%$, respective to stoichiometric KTN. Dotted and dashed lines were included at predominate diffraction angles for perovskite and pyrochlore phases, respectively. $\mathrm{X}$-ray pole figure plots were performed on several candidate films to further inspect their crystal quality and orientation. Figure 5 shows representative pole figure plots from high quality (100) and (110) oriented films.

The XRD results in Fig. 2 show excellent perovskite crystal quality (especially on substrates of similar lattice constant to bulk KTN). No pyrochlore was detected in any of these films. Pole figure orientation data show oriented perovskite KTN (100) on STO (100) and highly oriented KTN (100) on LSAT (100) and $\mathrm{MgO}$ (100), as well as oriented KTN (110) on YSZ (100). No attempt was made to remove the amorphous native oxide present on the silicon sample surface prior to deposition, so a predominately amorphous KTN film was found with only a trace of broadly (110) oriented perovskite. A future surface pretreatment study will be conducted to attempt the growth of high quality KTN on Si.

Figure 3 shows XRD results from the $96 \% \mathrm{~K}$ composition KTN films. Generally, this set of films showed similar 


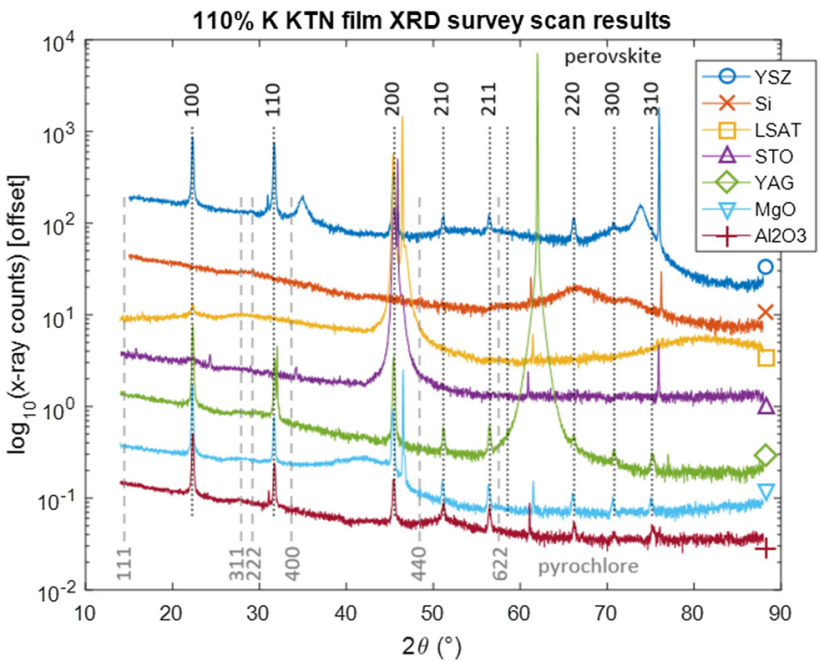

FIG. 2. XRD survey integrated intensity results for KTN films of $110 \% \mathrm{~K}$ concentration. Gray dotted and dashed lines show prominent diffraction lines for perovskite and pyrochlore phases, respectively.

results as the $110 \% \mathrm{~K}$ case, but with trace to small amounts of pyrochlore. Crystal quality showed a preference for equivalent lattice constant substrates closest to KTN.

Figure 4 shows XRD results for the $83 \% \mathrm{~K}$ composition KTN case. In these very understoichiometric films pyrochlore dominated, with only trace amounts of perovskite for substrates close to KTN's lattice constant.

Figure 5 shows pole figure plots of KTN(100)||LSAT(100) and $\mathrm{KTN}(110) \| \mathrm{YSZ}(100)$ as a proof-of-concept of the in-plane orientation of the films. It is clear from the pole figures that the films are oriented both in- and out-of-plane with epitaxial relationships KTN(100)|KTN[001]|LSAT(100)|LSAT[001] and KTN(110)|KTN[1-10]||YSZ(100)|YSZ[1-10]. Pole figure plots of $110 \% \mathrm{~K} \mathrm{KTN}$ on $\mathrm{SrTiO}_{3}$, LSAT, and $\mathrm{MgO}$ samples are all of similar form to Fig. 5(a), but with varying $2 \theta$ scans of (100) orientation showing full width at half max values of $0.071^{\circ}$, $0.151^{\circ}$, and $0.164^{\circ}$, respectively. Their (110) orientation $\varphi$ full

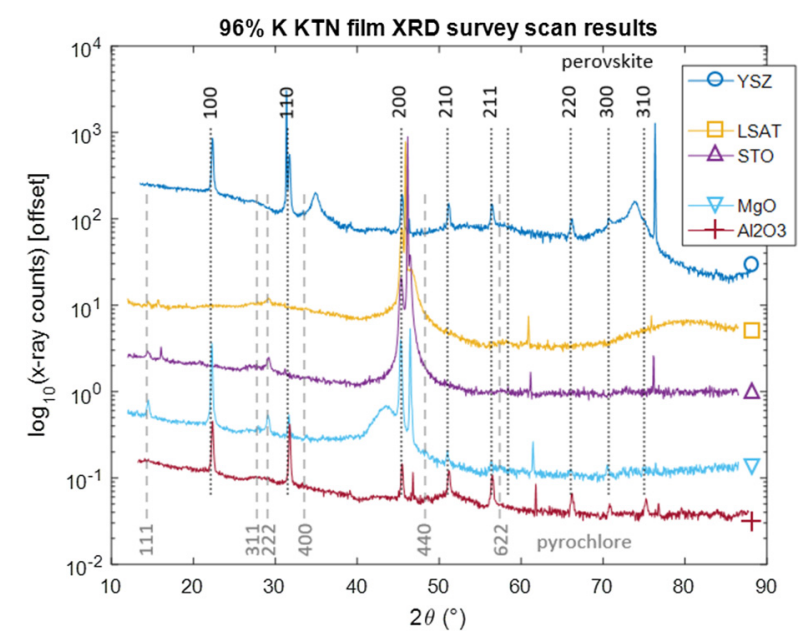

FIG. 3. XRD survey integrated intensity results for KTN films of $96 \% \mathrm{~K}$ concentration. Gray dotted and dashed lines show prominent diffraction lines for perovskite and pyrochlore phases, respectively.

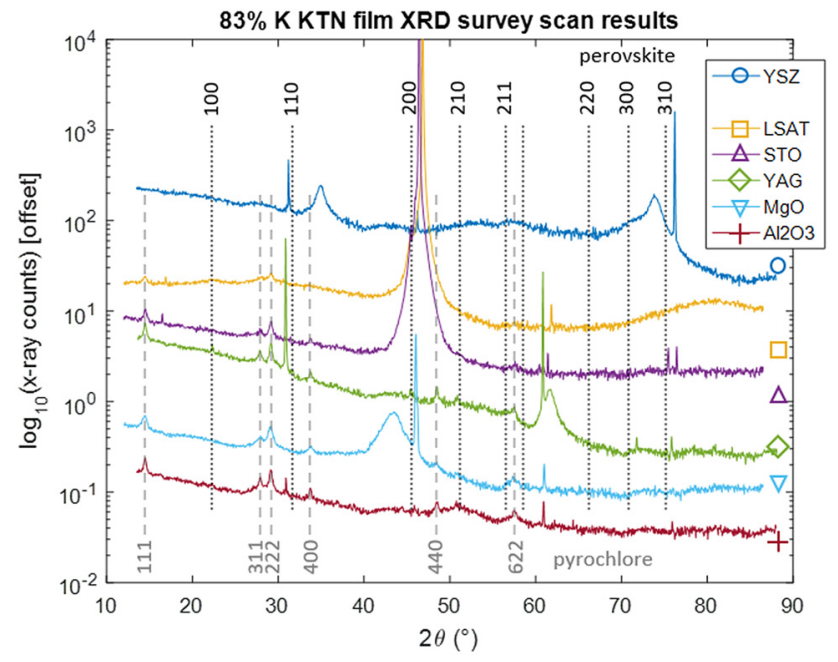

FIG. 4. XRD survey integrated intensity results for KTN films of $83 \% \mathrm{~K}$ concentration. Gray dotted and dashed lines show prominent diffraction lines for perovskite and pyrochlore phases, respectively.

width at half max values were $0.52^{\circ}, 1.46^{\circ}$, and $6.9^{\circ}$, respectively. This indicates that KTN crystal quality improves with reduced substrate strain. Figure 5(b) shows a clearly sharp (110) orientation.

Table I summarizes our results and shows the substrates listed in an order of increasing apparent atomic spacing. The excess potassium and nearly stoichiometric potassium cases showed a strong perovskite preference, while the potassium deficient case showed a strong pyrochlore preference for all substrates. This underlines the importance of proper composition control in the deposition of phase pure KTN.

The YSZ substrate was (100) oriented, but KTN preferred to grow at (110) due to its matching surface lattice constant. If the native oxide on $\mathrm{Si}$ (100) could be removed prior to deposition, its lattice constant might provide a good host for KTN (110), similar to YSZ, possibly of higher crystalline quality. Ge may also potentially yield a slightly better KTN (110) film. We anticipated KTN to fit neatly three times within the YAG (100) lattice, but its KTN films only showed unoriented polycrystalline material. We expected the $\mathrm{Al}_{2} \mathrm{O}_{3}$ (1102) rectangular surface arrangement to closely fit four KTN lattice constants in one direction and one in the other for an average of $4.323 \AA$, but it yielded unoriented polycrystalline material, with some (100) oriented polycrystalline portion. The possibility to controllably tune orientation and strain parameters of KTN films is an important step towards device integration.

Figures 6(a) and 6(b) show SEM images of $96 \%$ and $83 \%$ K KTN films on LSAT, respectively. The stark difference between the predominately (100) single orientation perovskite texture from Fig. 6(a) and unoriented polycrystalline texture from Fig. 6(b) is shown in the magnified images of Figs. 6(c) and 6(d). All four of the images presented in Figs. 6(a)-6(d) are horizontally and vertically oriented to the substrate lattice vectors. These images typify the various conditions explored in this study and represent the two prevailing morphologies found. The stress ripples and cracks present in the single 
a)

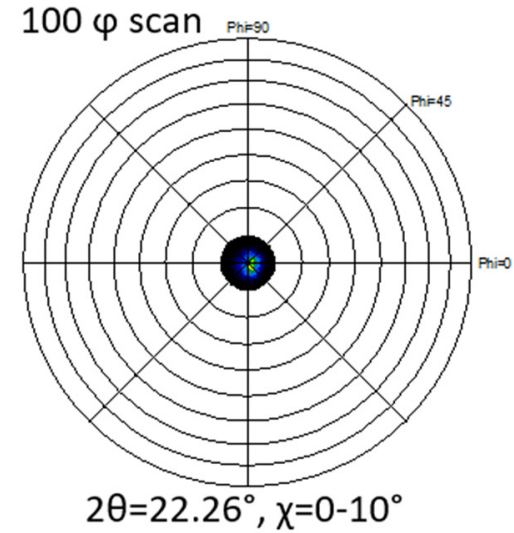

b)

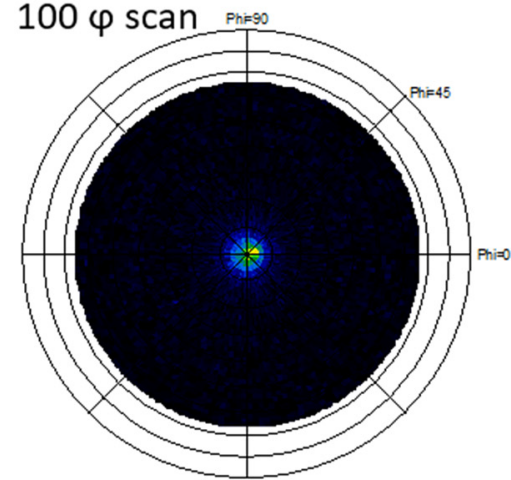

$2 \theta=22.26^{\circ}, \chi=0-10^{\circ}$

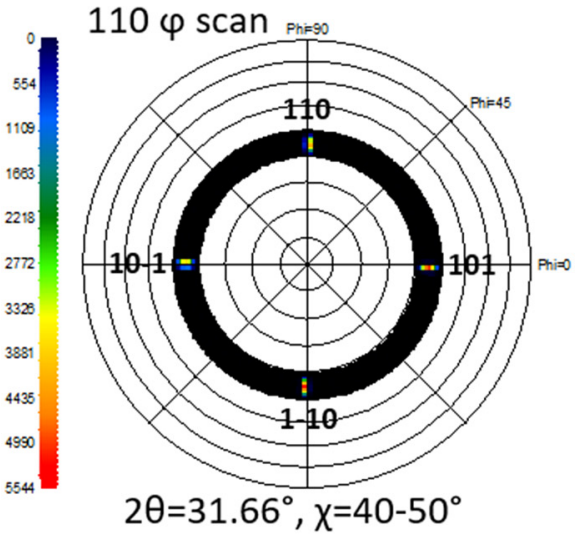

1928
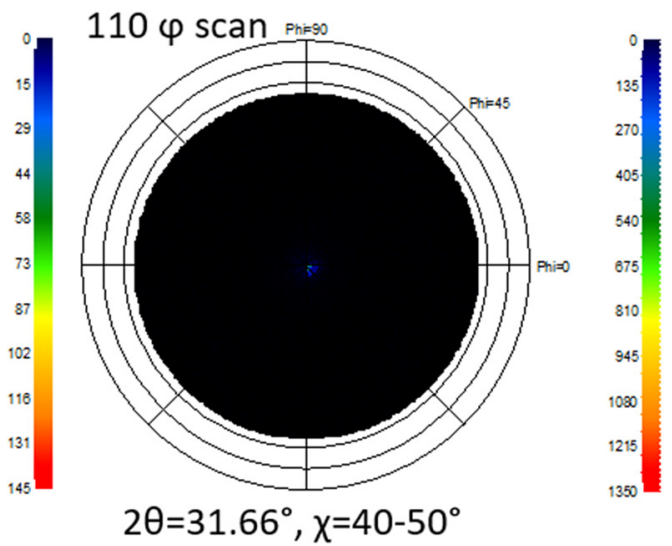

FIG. 5. Representative single crystal film and well oriented pole figure plots of (a) (100) 110\% K LSAT and (b) (110) 110\% K YSZ.
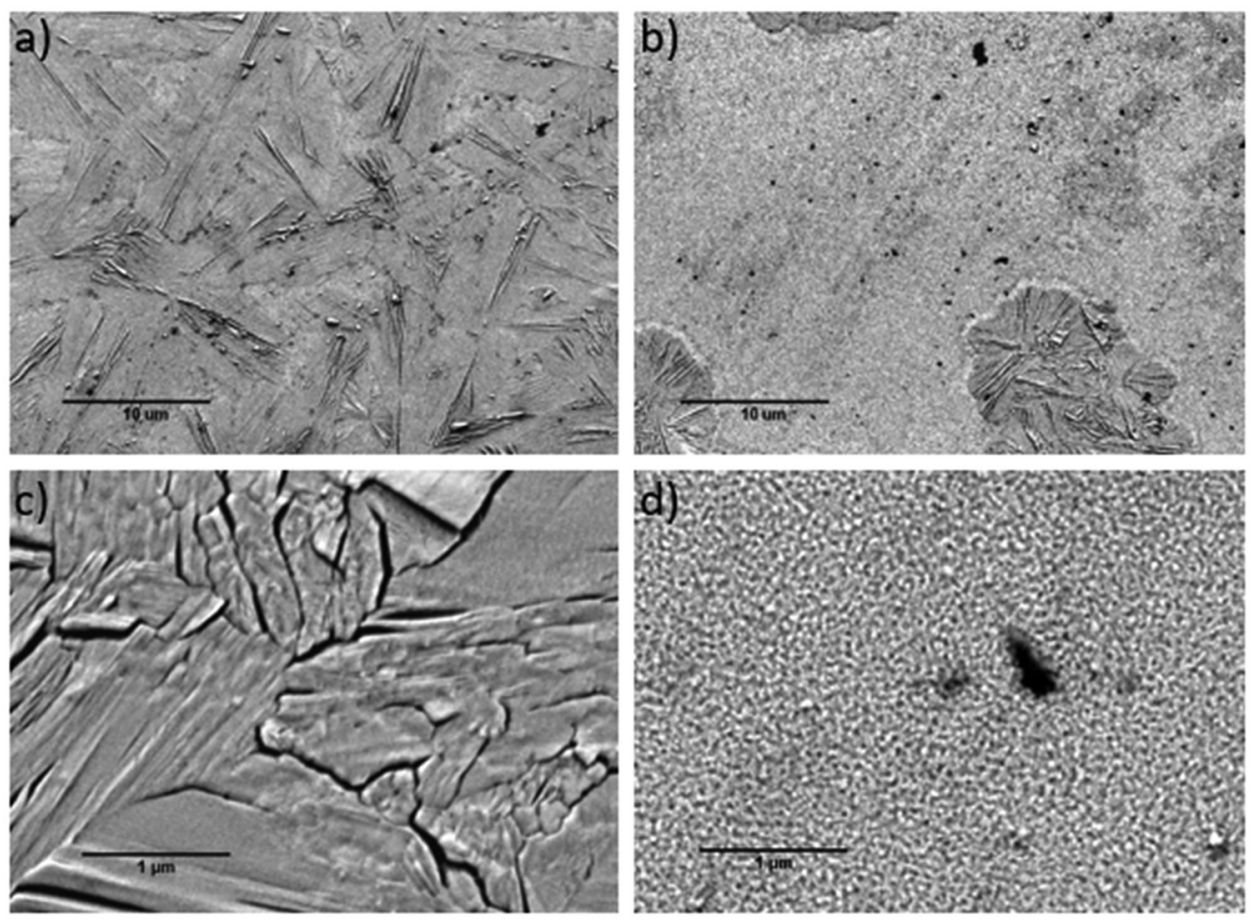

FIG. 6. SEM images for annealed KTN films of (a) $96 \%$ and (b) $83 \% \mathrm{~K}$ concentration on (100) LSAT substrate. Higher magnification images of (c) (100) single oriented perovskite and (d) unoriented polycrystalline pyrochlore are also shown. 
orientation perovskite images are likely a result of annealing films too thick to pseudomorphically withstand the thermally induced stress. The films are generally flat with no major out-of-plane crystallite protrusions.

\section{SUMMARY AND CONCLUSIONS}

We have shown that KTN thin films can be grown with high quality on a variety of substrates using ALD. The system exhibits compositional control well within the needs of EO applications. We show orientation control by choice of substrate and phase control by tuning the potassium content. The perovskite phase was prominent with excess potassium and nearly stoichiometric KTN, though even a slight potassium deficiency was enough to induce trace amounts of pyrochlore. Severely potassium deficient KTN resulted in a nearly pure pyrochlore phase. Crystal quality was highest when matched to bulk KTN's $3.996 \AA$ lattice constant. KTN (100) was obtained on STO (100), LSAT (100), and MgO (100). Furthermore, KTN (110) was obtained on YSZ (100), most probably due to strain minimization. In contrast to the $700-850{ }^{\circ} \mathrm{C}$ postgrowth anneals or sustained growth temperature range needed to obtain perovskite $\mathrm{KTN}$ with other methods, we were able to achieve high perovskite concentration films with only a $650{ }^{\circ} \mathrm{C}$ postanneal. We believe these findings are an important step towards monolithic device integration of KTN.

In the future, we plan to measure the capacitance versus voltage across temperature and Ta composition of ALD KTN films on various substrates to map the $T_{C}$ of our process to see if there is a substrate induced variability. We then plan to measure the EO coefficient of KTN thin films about $\mathrm{T}_{\mathrm{C}}$ near room temperature.

\section{ACKNOWLEDGMENTS}

The authors would like to thank James W. Pattison, Milena B. Graziano, and Ryan O'Donnell for helpful experimental discussions and assistance characterizing the films presented. Part of the project was conducted within the RIDSEM-project (financed by the Research Council of Norway, No. 272253).

${ }^{1}$ J. E. Geusic, S. K. Kurtz, L. G. Van Uitert, and S. H. Wemple, Appl. Phys. Lett. 4, 141 (1964).

${ }^{2}$ F. S. Chen, J. E. Geusic, S. K. Kurtz, J. G. Skinner, and S. H. Wemple, J. Appl. Phys. 37, 388 (1966).
${ }^{3}$ T. Imai, M. Sasaura, K. Nakamura, and K. Fujiura, NTT Rev. 5, 1 (2007), see https://www.ntt-review.jp/archive/ntttechnical.php?contents= ntr200709sp1.html.

${ }^{4}$ P. Guenter, Ferroelectrics 24, 35 (1980).

${ }^{5}$ A. Yariv and P. Yeh, Optical Waves in Crystals (Wiley, New York, 1984).

${ }^{6}$ S. Triebwasser, Phys. Rev. 114, 63 (1959).

${ }^{7}$ J. A. McCaulley, V. M. Donnelly, M. Vernon, and I. Taha, Phys. Rev. B 49, 7408 (1994).

${ }^{8}$ R. Soref and B. Bennett, IEEE J. Quantum Electron. 23, 123 (1987).

${ }^{9}$ W. A. Bonner, E. F. Dearborn, and L. G. Van Uitert, Ceram. Bull. 44, 23 (1965), available at https://bulletin-archive.ceramics.org/1965-01/.

${ }^{10}$ D. Rytz and H. J. Scheel, J. Cryst. Growth 59, 468 (1982).

${ }^{11}$ X. Wang, J. Wang, and B. Liu, Adv. Mater. Res. 306-307, 352 (2011).

${ }^{12}$ S. Hirano, T. Yogo, K. Kikuta, T. Morishita, and Y. Ito, J. Am. Ceram. Soc. 75, 1701 (1992).

${ }^{13}$ S. Wang, J. Zhao, T. Zhou, L. Wang, and A. Kuang, Ferroelectrics 195, 5 (1997).

${ }^{14}$ D. Bao, A. Kuang, and H. Gu, Phys. Status Solidi A 163, 67 (1997).

${ }^{15}$ C. J. Lu and A. X. Kuang, J. Mater. Sci. 32, 4421 (1997).

${ }^{16}$ J. Buršı́ k, I. Drbohlav, P. Vaněk, and V. Železný, J. Eur. Ceram. Soc. 24, 455 (2004).

${ }^{17}$ J. Buršsı'k, V. Železný, and P. Vaněk, J. Eur. Ceram. Soc. 25, 2151 (2005).

${ }^{18}$ S. Yilmaz, T. Venkatesan, and R. Gerhard-Multhaupt, Appl. Phys. Lett. 58, 2479 (1991).

${ }^{19}$ H. M. Christen, L. A. Boatner, J. D. Budai, M. F. Chisholm, L. A. Géa, P. J. Marrero, and D. P. Norton, Appl. Phys. Lett. 68, 1488 (1996).

${ }^{20}$ L. A. Knauss, K. S. Harshavardhan, H. M. Christen, H. Y. Zhang, X. H. He, Y. H. Shih, K. S. Grabowski, and D. L. Knies, Appl. Phys. Lett. 73, 3806 (1998).

${ }^{21}$ A. Rousseau, M. Guilloux-Viry, E. Dogheche, M. Bensalah, and D. Remiens, J. Appl. Phys. 102, 093106 (2007).

${ }^{22}$ W. Yang, Z. Zhou, B. Yang, Y. Jiang, H. Tian, D. Gong, H. Sun, and W. Chen, Appl. Surf. Sci. 257, 7221 (2011).

${ }^{23}$ C. H. Jung, M. S. Choi, K. S. Lee, and D. H. Yoon, Opt. Mater. 34, 269 (2011).

${ }^{24}$ W. Yang, Z. Zhou, B. Yang, Y. Jiang, Y. Pei, H. Sun, and Y. Wang, Appl. Surf. Sci. 258, 3986 (2012).

${ }^{25}$ A. Bouyasfi, M. Mouttalie, V. Demange, B. Gautier, A. Grandfond, S. Députier, S. Ollivier, L'H Hamedi, and M. Guilloux-Viry, Appl. Surf. Sci. 258, 9297 (2012).

${ }^{26}$ B. M. Nichols, "Structural, dielectric, and optical properties of potassium tantalate niobate thin films prepared by metalorganic chemical vapor deposition," dissertation (Northwestern University, 2000).

${ }^{27}$ S. M. George, Chem. Rev. 110, 111 (2010).

${ }^{28}$ H. H. Sønsteby, H. Fjellvåg, and O. Nilsen, Adv. Mater. Interfaces 4, 1600903 (2017).

${ }^{29}$ O. Nilsen, V. Miikkelainen, K. B. Gandrud, E. Østreng, A. Ruud, and H. Fjellvåg, Phys. Status Solidi A 211, 357 (2014).

${ }^{30}$ E. Østreng, H. H. Sønsteby, T. Sajavaara, O. Nilsen, and H. Fjellvåg, J. Mater. Chem. C 1, 4283 (2013).

${ }^{31}$ E. Østreng, H. H. Sønsteby, S. Øien, O. Nilsen, and H. Fjellvåg, Dalton Trans. 43, 16666 (2014).

${ }^{32}$ H. H. Sønsteby, O. Nilsen, and H. Fjellvåg, J. Vac. Sci. Technol. A 34, 041508 (2016).

${ }^{33}$ M. M. Hsu, A. Marinelli, C. Merckling, M. Pantouvaki, J. Van Campenhout, P. Absil, and D. Van Thourhout, Opt. Mater. Express 7, 2030 (2017). 